\title{
A Phenomenological Analysis of Managerial Capability in SMEs in Nigeria
}

\author{
*Gift U. Roman \\ Postgraduate student, Leeds Beckett University, United Kingdom \\ ${ }^{*}$ Corresponding Author Email: gift.roman@naoc.agip.it \\ Martin Samy PhD \\ Professor of Accounting, Leeds Beckett University, United Kingdom \\ Email: M.A.Samy@Leedsbeckett.ac.uk
}

\author{
Alaa Soliman PhD \\ Senior Lecturer, Leeds Beckett University, United Kingdom \\ Email:a.soliman@leedsbeckett.ac.uk
}

\section{Doi:10.5901/mjss.2016.v7n3p125}

\section{Abstract}

As concluded by researchers change process of transformation involves implementation of better strategies to have sustainable competitive advantage. Non financing strategies should be adopted rather than solely relying on financial indices as observed in most Nigerian SMEs. This research argues that managerial capabilities which include HR competencies and skills are vital for business survival as such employers should develop and execute strategies to prioritise capabilities. The aim of this study is to evaluate phenomenologically an interpretation of managerial capability as a non-financial dimension of Organisational Health in relation to the growth of SMEs in the Nigerian context. It is pertinent to know that managerial capability which is one of the soft factor dimensions has already identified skills and competencies in related literature. This interpretive phenomenological study adopted an inductive approach using the philosophical paradigm of constructivism and semi-structured interviews for data collection. Nvivo software was used for the data analysis. The study's key findings show that managerial capability has the highest percentage and seems to be the ultimate foundation of Organisational Health. It further shows that connectivity and relationship exist between dimensions of Organisational Health especially capability and leadership on the one hand and accountability and reporting structure on the other hand which all have influence on the growth of SMEs. However, capability and accountability are found to have stronger influence on SMEs' growth compared to leadership and reporting structure. This study reveals that the successes of SMEs are closely tied to socio-psychological processes and not only to financing support.

Keywords: Financial Indices, Non-Financial Indices, Organisational Health, Managerial Capability, Growth

\section{Introduction}

Organisations are faced with challenges that hinder or truncate their growths therefore these challenges are warning signs of trouble ahead (Davidson, 2009). The challenges as argued by Davidson (2009) include emergence of reduction of working capital, lost values on the part of employees, poor and overloaded information system which leave the administration of the company in disarray. These challenges have been attributed to sole reliance on financial indices in most SMEs in Nigeria (Jaja, 2009). Sharing a parallel view, Almus (2004) argued that all rapidly or moderately growing companies face critical transition points in their life cycle which should be recognised, confronted and managed successfully in order to move on to the next phase of growth. This was evident in a number of studies such as Davidson, (2009) Jaja, (2009), Oparama, (2010) and Ofeogbu and Akanbi, (2012).

To overcome the above challenges, organisations should have insight and management capability to recognise that their companies are encountering critical growth transition problems in their life cycle in order to better manage their way through these crisis points successfully and keep their businesses on track for future growth continuity( Argote and Ingram, 2000; Amir, 2012 ). In recognising the challenges and proffering solutions, Amir (2012) suggested that the organisation's structure and management needs may have to be reviewed, a governance advisory board established, managers with professional management skills appointed, proper strategic and business planning systems established 
and information and communication systems upgraded. Nelson (2006) in agreement with Amir (2012) posited that the management skills should be such that will establish a clear sense of direction as regards the organisational vision, align employees to the actualisation of that vision, motivate and inspire the employees to perform and produce changes as the need arises. The issue of change as highlighted by Nelson (2006) was given credence by Okurame (2009) in the assertion that another area that managerial capability is of great necessity is as regards change due to the operational reality of contemporary organisations being under the pressure of escalating domestic and international competition, market shrinkage and swift advancement in information technology.

This study is a phenomenological evaluation of managerial capability as one of the dimensions of Organisational Health and growth of SMEs in Nigeria. It adopts a constructivist ontological paradigm using a qualitative inductive approach which believes that social phenomena are actually constructed by social actors (Baron and Banaji 2006). The constructivist paradigm is adopted because human interest is the main driver of the science of human understanding. Based on the aim of this study, the research design is apt to explore and increase general understanding of situations. It allows the researcher to get close to participants and their thinking in order to scrutinise the entire research problem.

Therefore from gathered rich data, ideas are induced. This approach is used to holistically understand human experiences in context-specific setting using strategies like case studies in Nigeria. Chew and Chan (2008) argued that constructivist paradigm requires clear knowledge about the phenomena under investigation. It is therefore evident that valuable information may be missed by strictly relying on objective reality. The exploratory nature of this study is consistent with similar researches such as Amabile (2009), Jaja (2009) and Eleni et al. (2011), as it reveals the perception of employees as regards to managerial capabilities inclusive of change in relation to its influence on the survival and success of SMEs.

\section{Literature Review}

The influence of managerial capability as one of the dimensions of Organisational Health on growth entails organisational leadership that has the capability to influence employees' perception of change; nevertheless the perception of change as being either necessary to be effected or nuisance to be avoided depends on the managerial capabilities of senior executives and line managers during transformational processes (Cummings and Worley, 2001). In conformity with the assertion by Cummings and Worley (2001), Zheng et al. (2010) added that the organisational leadership has to skilfully apply managerial capabilities, map out each step during three interconnected stages in order to bring about change that will positively influence Firm Growth; that is the survival and success of firms. Firstly the organisational leadership has to conceptualise the new strategic course; secondly it has to motivate the organisational employees by expressing passion and optimism and thirdly it has to effectively and efficiently distribute all resources needed to facilitate the change process of transformation. This is in line with the AMO (Ability, Motivation and Opportunity) theory which is the ability to perform, motivation to perform and opportunity to perform. The AMO theory explains the connection between high performance HR practices and employee behavioural outcomes in organisations (Appelbaun et al., 2000). This theory predicts that managers can improve employee performance by positively influencing employees' ability $(A)$ to perform, motivation (M) to perform and opportunity $(O)$ to perform (Boxall and Purcell,2008). Consequently according to the AMO theory, organisational growth in form of survival and success is a function of employee ability, motivation and opportunity to participate in organisational activities such as decision making.

Ofeogbu and Akanbi (2012) observed that change process of transformation is necessary and should be encouraged in organisations due to its positive effects on Firm Growth. However such change processes are faced with stiff resistance and oppositions in most Nigerian SMEs. Nevertheless Bass and Rigio (2006) contended that with managerial capabilities, employers should develop and execute strategies that will encourage change process. Augustine (2013) posited that for Firm Growth to be actualised, failing organisations should reconsider the capabilities of managers and insist on change where there are deficiencies irrespective of the complexities involved in change process. Confirming the complexities in change process, Heward et al. (2007) observed that the planning of change becomes complex with many contingencies, steps and sub steps. In some cases, organisations may go through cycles of change without proper planning and implementation or worst still skip one or more steps of the action plan that may have been erroneously perceived as trivial. Such experiences can result in those responsible for the execution of plans being uninterested. This may hinder future change even when the change is suitable and imperative for the survival of the organisation in the market.

Yuki (2002) therefore argued that it is the organisational leadership that holds the key to a successful change management and ultimately Firm Growth with full optimisation of the needed managerial capabilities/competencies. The dynamic capability framework as explained by Teece (2009) entails the capabilities necessary to sustain superior firm 
performance and ultimately growth in rapidly changing environments. This depends on a firm's managerial resources.

These resources include the capability of the firm to recognise problems and trends, direct and redirect resources, reshaping organisational structures and systems to create, address and sustain technological opportunities while staying aligned with customer and employee needs. To sustain superior performance and competitive advantage, the dynamic capability framework identified three classes of managerial skills namely; to sense opportunities, seize opportunities and reconfigure resources. An important managerial capability/ skill is learning. Wang (2008) argued that organisational learning is both a resource and dynamic capability of the firm. According to Bontis et al. (2002), learning is a valuable organisational skill to be desired hence provided evidence of a positive relationship between learning and performance with learning at three levels; individual, group and organisation. Teece (2009) distinguished five stages of organisational learning process namely information acquisition, information dissemination, shared interpretation, declarative memory and procedural memory. It is necessary to be acquainted with learning as part of managerial skills and competences that will aid in the actualisation of Firm Growth as observed by Shawn et al. (2010). They argued that certain managerial abilities are required to implement the processes in order to have a positive effect on firm performance and ultimate growth.

Building on Teece (2009) argument, Mark et al. (2009) provided evidence that the whole process of organisational learning engineered by prerequisite managerial abilities produces better performance. These results were further advanced by Zheng et al .(2010) who discovered that dynamic managerial capability is essential to bring to bear organisational learning which positively affects performance for individuals and teams across organisational structures.

Other researchers such as Edgar and Alan (2005), Egbu et al. (2005) and Wang (2008) concurred maintaining that organisational learning is both a resource and a dynamic capability itself for a firm. Deviating to an extent in respect of managerial capability and its influence on Firm Growth, Hung et al. (2010) argued that organisational learning does not directly influence organisational performance as asserted by previous scholars but enhances dynamic capability as regards knowledge accumulation and innovation. It is the managerial capability that influences growth. Zolo and winter (2002) therefore advised that appropriate mechanisms, skills should be imbibed to foster organisational learning which is a basis for gaining sustainable competitive advantage and positively influencing a firm's performance and subsequent growth.

Tan and Nasurdin (2011) had parallel views with Zolo and Winter (2002) but are in doubt if such managerial skills and competencies exist in Nigerian SMEs considering the alarming rate of failures, seizures and mortality rates. Lending support to Tan and Nasurdin (2011), Okurame (2009) asserted that learning is a continuous process to improve organisational behaviours which include managerial skills, performance and foster growth but the reverse is the case in most Nigerian SMEs as they often rely on obsolete knowledge. Bonny (2005) attributed the reliance on obsolete knowledge to insufficient funds for training to improve knowledge base, have a competitive advantage and foster firm growth.

On the contrary, Augustine (2013) disagreed with the reason (insufficient funds) given for lack of knowledge update but attributed this occurrence to ignorance and lack of implementation of prerequisite managerial capabilities and knowledge acquisition that will propel competitive advantage and foster Firm Growth. Consequently, Jogulu (2010) stressed the need for managers in Nigerian SMEs to broaden their horizon in respect of knowledge acquisition and managerial capabilities that will ensure sustainable Firm Growth. There are other skills and areas that require the exhibition of managerial capabilities as will be discussed in subsequent literature.

Another essential managerial competence and skill in sustaining competitive advantage is managerial coaching (Obisi,2011) which is described by Hayton (2005) as an effective leadership practice that facilitates learning process of the employees for better performance and more effectiveness; thus benefiting mostly the employee, the manager and organisation at large. Hayton (2005) asserted that managerial coaching can bring competitive advantages for organisations through employees' empowerment and motivation for performance, bringing more satisfaction and commitment thereby fostering growth. As a result, managerial coaching is considered an essential managerial competence that organisations increasingly choose to invest in to develop actions meant to build this set of skills (Laohavichen et al. 2009). However the review of Hayton (2005) separates managerial coaching into two approaches; the behavioural model as suggested by Baron and Banaji (2006) and the skills lattitudes model (Mark et al., 2009). Behavioural model conceptualises managerial coaching based on actions displayed by managers which are further categorised as empowering and facilitating behaviours. Such behaviours include open communication, provision and request for feedback from employees, informing, continuous assessment, empowerment, offering opportunities for development and delegation (Kelloway et al., 2012). The skills model describes the way the coaching manager displays skills being able to support a coaching mentality like valuing people, accepting ambiguity within the workplace and appreciation/encouraging of team work (Rayman, 2004). 
Human resource skills entail managerial skills which requires that personnel be managed, developed and rewarded based on actual performance rather than on managers' flawed perceptions of employees' performance (Omachonu and Einspruch, 2010). This will enhance organisational effectiveness and in turn growth. In reality, it has been observed that managers' perceptions and decisions about employee performance are often systematically biased. Consistent with this reasoning, performance declines clearly need to be identified so that appropriate remedial measures such as on the job coaching, job redesign, motivation or disciplinary action can be undertaken (Rahmati et al. 2012).

Managerial capability involves human relation skills consisting of skills exhibited in dealing with employees (Hitt et al., 2006). Human relation skills as observed by Jaja (2009) are all encompassing inclusive of Emotional Intelligence (El), self-management, time management and synergy and conflict management. Sharif et al. (2010) contended that Emotional Intelligence (EI) is a human relation skill/ competence required by leaders in exhibiting managerial capabilities to foster Firm Growth. Whitener (2006) describes El as the ability to understand your own emotions and that of your followers. It enables you to modify your feelings and influence what happens in your environment. Contrary to this, in most Nigerian organisations, some leaders understand only their own emotions but not that of their followers (Oparanma, 2010). Meanwhile El is particularly crucial for leaders and even subordinates in Nigerian SMEs due to work demands, increased family demands, financial demands, relationship demands, personal development, team performances and problems associated with underdevelopment in the country (Cheng et al., 2010). Obisi (2011) contended that managers in particular need high El since they represent the organisation in relating with customers and competitors, interacting with people within and outside the organisation and setting the tone for employee morale.

Success in sales requires El which is the ability to understand customers and provide service to them (Robbins and Judge, 2011). Management of El will help in developing interpersonal skills to work effectively in the organisation (Wood, 2005). According to Wood (2005), organisations loose customers because of lack of El; that is customers are dissatisfied due to poor services rendered to them. This leads to their exit. Rahman (2004) asserted that El is linked to Social Network Theory, Social Exchange Theory and Social Learning Theory which are all under sociological theories. This link is appropriate because El as a social construct deals on understanding emotions and developing relationships which are sensitive areas that organisational management needs competence (Tanveer, 2010). Rahmati et al. (2012) views the Social Network Theory as based on the principle of social interaction and concerned with relationships between interacting entities.Interaction and relationships between employees and management exist in all organisations. Therefore the interaction ought to be fruitful to yield expected results hence $\mathrm{El}$ is required to understand emotions of the different entities (Durst and Wilhem, 2011). According to Ahiauzu (2011), this theory which has reshaped management theory and practice holds that social factors are more important for both performance and morale. This social network stresses on the importance of linkages among a defined set of persons. Salami (2008) posited that organisations consist of people who constantly interact. These interactions in organisations are the basis for the performance and ultimate growth of the organisation. The authors further asserted that El which focuses on understanding feelings and forming relationship among members of an organisation is associated with the Social Network Theory. The underlining assumption between actors of the Social Network Theory is the social man concept (Sharif et al., 2010). This concept holds that man exists within a web of relationships and it is the path way that gave rise to the human relations movement. Zapf (2002) in affirming the need for El contended that it comprises of five factors which include intrapersonal skills, interpersonal skills, adaptability, stress management and general mood. Intrapersonal skills refer to the ability of being aware and understanding one's emotions, feelings and ideas. It is sub divided into self-regard, emotional self-awareness, assertiveness, independence and self-actualisation.

Sharif et al. (2010) describe interpersonal skills as the ability of being aware and understanding emotions and feelings of others. It is sub divided into empathy, social responsibility and inters personal relationship. Teece (2009) states that adaptability is concerned with the ability of being open to changes in feelings depending on the situation. This includes flexibility and problem solving. According to Wang (2008) stress management refers to the ability to cope with stress and control emotions. It consists of factors like stress tolerance and impulse control. General mood as described by Avolio et al. (2004) is concerned with feeling and expressing positive emotions and being optimistic. It comprises of optimism and happiness. All the aforementioned skills, competencies and talents constitute managerial capability which is a soft factor dimension of Organisational Health that has positive influence on Firm growth as revealed in already discussed literature.

Anugwom (2009) contended that self-management refers to how well one controls emotions, impulses and resources. As part of self-management, disruptive impulses have to be kept in check with the display of honesty and integrity, flexibility in times of change, maintenance of the drive to perform well and seizing opportunities hence remaining optimistic even after failure. Such ones are role models, self-coaching, positive thinkers who set personal goals and manage change. 
According to Luthans and Youssef (2007), a leader with self-management would not suddenly decide to fire an employee because of one difference of opinion but will rather exercise self-control. To lend support to Luthans and Youssef (2007), Wang (2008) attributed the high labour turnover in most Nigerian SMEs to lack of self-management on the part of employers and leaders. Self-management enables leaders to manage impulsive feelings and distressed emotions, think clearly, stay focused under pressure, composed, positive, and unflappable in challenging moments. Another mundane example is time management. As stipulated by Barlett (2011), this concerns working according to daily scheduled demands. The attitude of both employers and employees is very appalling in relation to time management in Nigerian SMEs (Baridam and Nwibere, 2008). Avey et al. (2012) observed that in developed economies, time is of essence hence time management is a valuable human resource tool. The time allotted for set activities is usually respected and kept. On the contrary, procrastination is the order of the day in most Nigerian organisations. This goes a long way in affecting output on the job. Pawar and Eastman (2009) contended that this as well may be one of the reasons for the high level of failures, stagnation and increased mortality experienced in Nigerian SMEs. The time value of money in respect of a job done today and that done days after may not be the same. Further observations by Barney (2005) in Nigerian SMEs are that employees report to work late. Jobs are not done as at when due. All this affect efficiency in organisations and ultimately growth.

Baron and Banaji (2006) showed in their study that supportive relationships are good for Organisational Health. Davidson (2009) however asserted that dealing with difficult people and maintaining on-going negative relationships is actually detrimental to the health of the organisation. To reduce or eliminate such relationships that are filled with conflicts may actually not bring about lasting solutions as far as the health of the organisation is concerned. Considering that synergy is important in accomplishment of organisational goals, Battilana and Casciaro (2012) suggested that managers should develop skills that will enable them to carry everyone along in the achievement of such goals. Synergy is important (Ireland et al., 2009) because teams enhance performance, increase responsiveness to customers hence gain competitive advantage and contribute to organisational effectiveness and health (Nelson, 2006). Ireland et al. (2009) suggested that managers should have certain skills and capabilities bearing in mind that every organisation consists of people from different cultures, with different personalities, working with different speed with different emotions having good/bad days and being mutually responsible for end results. Barney (2005) argued that to sustain competitive advantage and subsequent growth in the organisation, certain managerial skills are necessary for managing teams within the organisation. They include conflict management skills, negotiation skills and skills for handling difficult team members.

Kavanagh and Ashkanasy (2006) posited that conflict management skills are necessary to curb functional and dysfunctional conflicts. According to the authors, functional conflict is also known as constructive conflict which increases information and ideas, encourage innovative thinking, unravel different points of views, reduce stagnation and help the employees to work towards actualising organisational goals. On the other hand, dysfunctional conflict is characterised by tension, anxiety, stress, reduced trust, poor decisions due to distorted information, lack of innovation, stagnation, business as usual syndrome and blocks an organisation from actualising its goals. It requires more efforts and resources to get a task done due to conflict (Ibok, 2009).

Battilana and Casciaro (2012) suggested that a manager should be equipped with the right managerial skill depending on the existing conflict orientation. The different conflict orientations include dominance (want to win), collaborative (finding a solution that satisfies everyone), compromise (splits the differences), avoidance (back away) and being accommodative (focus on the desire of the other person). Battilana and Casciaro (2012)contended that collaborative orientations provide more positive long-term benefits than the others. Bowen and Ostroff (2009) described four approaches to conflict as the win/win situation (both parties feel satisfied), win/lose situation (one party gets satisfied), lose/lose (neither party gets satisfied) and the lose/win situation (the other party gets satisfaction). There is no best way to handle conflicts. It therefore depends on the situation. According to Chew and Chan (2008), there are five strategies for managing conflict which include mediation (identifying multiple possible alternatives and mutually select one that is acceptable to all involved parties and in the interest of organisation), arbitration (this requires provision of a safe and productive opportunity for the conflicted parties to air their disagreements). After careful listening to each party, formulate, define and provide solution to the parties. Besides mediation and arbitration, control, acceptance and elimination are also other strategies for managing conflict as identified by Chew and Chan (2008). Wood (2005) in consonance with the identification strategy by Chew and Chan (2008) described control as the tendency to bring tension and emotions down to a level at which productive discussion and negotiation can occur. The author added that humour is often an effective tool here as well as the use of temporary breaks or time-outs in the discussion between conflicted parties.

Haslinda et al. (2007a) also identified some strategies for managing conflict. The author contended that an acceptance decision can be made for conflict consequences that are negligible relative to organisational objectives; 
consequently no action will be required. According to the author, this strategy carries significant risk of latter escalation therefore should be combined with specific plans for monitoring the situation to ensure that the conflict remains at an acceptable level. Laohavichen et al.(2009) in agreement with the strategies of managing conflict described elimination as the strategy reserved for those conflicts that have become so dysfunctional that the organisation can no longer tolerate any negative impacts from them. It is often the last resort that involves the elimination of the conflicted parties from the organisation. As suggested by Laohavichen et al.(2009), a leader is advised to avoid situations that will generate conflict but support, harmonise, relieve tension, energise and facilitate team members in the organisation to sustain competitive advantage.

Ku et al. (2010) identified conflict as one of the prevailing circumstances in most Nigerian SMEs hence conflict management as a managerial skills in conflict resolution becomes imminent. Harrisson and Leitch (2005) posited that conflict arises where there is opposition, incompatible behaviour and antagonistic interaction entailing an individual blocking another from reaching desired goals. This according to Harrisson and Leitch (2005) happens frequently in Nigerian SMEs hence impedes growth. Nevertheless Gastro (2007) had a different opinion therefore argued that conflict is not always bad for an organisation hence it is not necessary that organisations should reduce all conflict. The authors further contended that conflicts are inevitable part of organisational life and are needed for the growth and survival of the organisation. Parallel to this, Haslinda et al. (2007b) contended that organisational conflicts reveal the deficiencies of employees and management hence are necessary ills that will ameliorate deficiencies. The authors therefore suggested that organisational management should possess managerial capabilities to curb conflicts rather than eliminating conflict which is almost impossible.

Sharif et al. (2010) revealed that a complete revamping of Nigerian SMEs in the knowledge and implementation of managerial skills and competencies is expedient if SMEs must grow as expected and compete favourably with other SMEs in the global economy. Akintajo (2010) however argued that the challenge in Nigerian SMEs is not in the knowledge of managerial skills and competencies as revealed by Sharif et al. (2010) but is in the implementation of what is already known. The author argued that Nigerian SME managers and leaders cannot claim ignorance of managerial skills and competencies. Jaja and Okwandu (2006) re iterated that the problem in majority of Nigerian SMEs is implementation.

Ku et al. (2010) stated some capabilities of leaders as suggested by Jim Collins' model of five levels of leadership. The model depicts five hierarchical levels. Level 1 describes a highly capable leader who makes productive contributions through talents, knowledge, skills and good working habits. Level 2 refers to team skills; possessing the ability to work in a team, contributing individual capabilities to achieve the team objectives and working effectively with other team members. Level 3 depicts the leader's skill to organise people and resources toward the effective pursuit and actualisation of organisational goals. At level 4 , the leader catalyses commitment and vigorous pursuit of a clear and unambiguous organisational vision stimulating higher performance standards. At level 5, the leader possesses levels 1 to 4 skills with an extra dimension blend of humility and professional as shown in Figure 1.

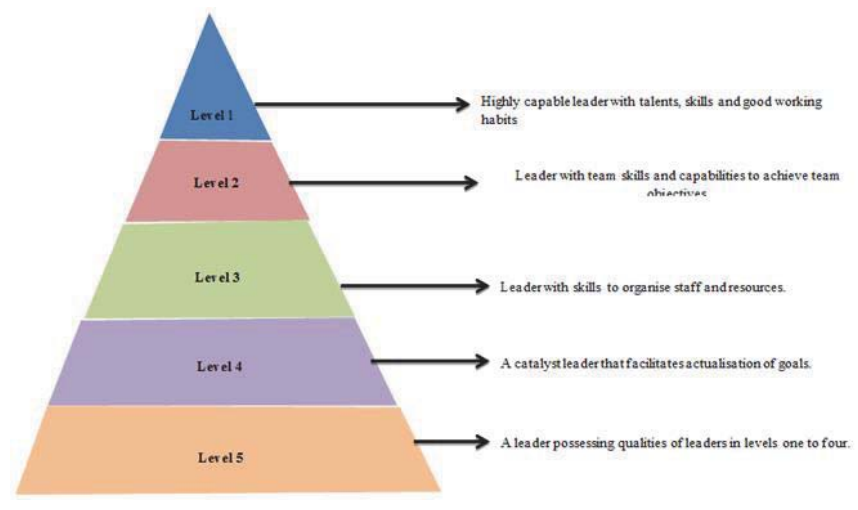

Figure 1. Levels of Leadership skills

Source: Modified from Ku et al. (2010)

From the foregoing, several authors have emphasised the importance of several skills, talents, competence which 
constitute managerial capability and human resource actions that require managerial capability all in a bid to increase performance and foster Firm Growth. They include Human Relations Skills encompassing emotional intelligence, selfmanagement, flexibility, synergy, conflict resolution, time management and employee coaching, team work and learning (Jantunen et al., 2005; Gastro, 2007; Balkundi and Harrison, 2006; Ireland et al., 2009; Yang, 2010; Jusoh et al., 2011 and Khalili, 2012).

The identified skills and capabilities in the empirical review of related literature are the sub-themes emanating from the theme in the findings of this phenomenological study. The sub-themes depicted in Figure 3 are constructively evaluated in relation to their influences on the survival and success of firms in the Nigerian perspective.

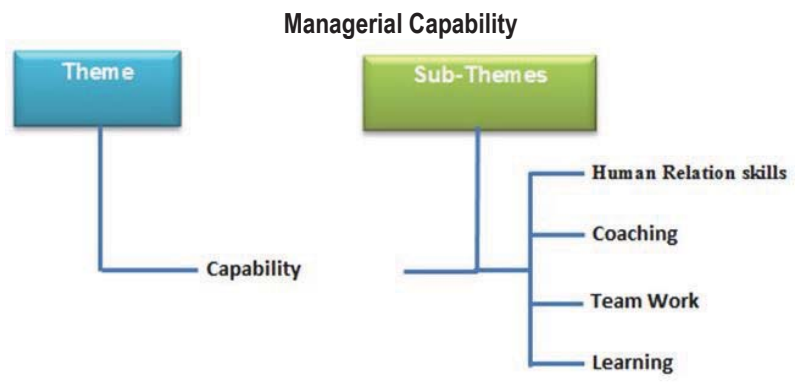

Figure 2. Managerial capability and sub-themes

\section{Methodology}

This study adopts a constructivist paradigm using a qualitative approach to inductively and holistically understand human experiences in context-specific setting; that is the Nigerian setting. The constructivist paradigm using a qualitative inductive approach believes that social phenomena are actually constructed by social actors (Baron and Banaji 2006). The data on managerial capability is gathered from human resources (social actors) to increase general understanding of situations and from gathered rich data, induce ideas. By adopting a qualitative approach, a clear knowledge about the phenomena under investigation is ascertained employing strategies such as case studies with the use of open-ended data and emerging data with the primary intent of developing themes and sub-themes from the data. Furthermore given the exploratory nature of this study on the phenomenological evaluation of managerial capability and growth and being consistent with similar researches in the field like Amabile (2009), Jaja (2009) and Eleni et al. (2011), a constructivist paradigm using a qualitative approach is apt for this study.

Craswell (2003) postulated that qualitative paradigm requires clear knowledge about the phenomena under investigation. This is then tested in its wider context over time. It is therefore evident that valuable information may be missed by relying solely on objective reality. Consequently, the constructivist paradigm was chosen to gather rich data from social actors who are the participants from the SMEs. Based on the nature of the research questions, this constructivist paradigm is apt. The research questions are;

1. What is the perception of the non-financial soft factor dimension of Organisational Health in the Nigerian manufacturing SMEs?

2. What is the influence of the non-financial soft factor dimension of Organisational Health on the non-financial measure of growth in the Nigerian manufacturing SMEs?

The constructivist paradigm allows exploring the soft factor dimension of Organisational Health in organisations which involves looking into the complexity of managerial capability, as it concerns the employees and ultimately Firm Growth. In addition, similar researches in the field like Amabile (2009), Jaja (2009) and Eleni et al. (2011) adopted the constructivist paradigm.

Preceding data collection was dissemination of information letters and consent forms. Information letters and consent forms were sent to the management of each of the SMEs. The consent forms were duly completed by participants and dates for the interviews agreed upon by participants in the respective SMEs. Data was collected through semi structured interviews. The interviews were conducted between April and September 2015 in the respective offices of the participants. An interview guide with questions was used as a basis for the semi-structured interviews. The interviews were tape recorded and written notes taken. A sample size of thirty participants was used in this study. The thirty participants were drawn from ten manufacturing SMEs in the Niger Delta region of Nigeria. The participants are drawn 
from SMEs because 95\% of all employees in the Nigerian labour market are in the SMEs as observed by Jaja (2009). Consequently, the SMEs have become key players in the Nigerian economy. SMEs constitute a priority area of the national economy and therefore an area of interest for this study. The selected SMEs are in the Niger Delta because a higher concentration of the SMEs lies in the Niger Delta region. The limited numbers of participants were considered apt for the study as the saturation point is expected to be achieved.

Manufacturing SMEs were selected because Aniete and Akpan (2012) observed that manufacturing SMEs have capabilities to meet market demands but with adoption of low formalised managerial practices. Consequently the need for improved managerial practices in the manufacturing SMEs is apt. In addition, studies by Aniete and Akpan (2012) and Akinruwa et al. (2013) focused on the manufacturing sector. Three participants were drawn from each of the ten manufacturing SMEs. Each of the three participants was drawn from the strategic, tactical (middle) and operational (lower) management levels respectively. Considering the aim of this study, it is apt to involve participants from all levels of management. In addition similar studies by Iveroth (2010), Vesterinen et al. (2012) and Aniete and Akpan (2012) consisted of participants from the management and lower levels of the organisation.

The accumulated data from the interviews were transcribed and coded. Nvivo software package was used for the coding process and data analysis. The coding process in this study involved sorting, integration and data reduction into themes otherwise known as codes. Coding was done in two stages; the Open Coding which is the initial categorisation of passages into codes which represented concepts and themes basic to understanding the interview questions and the axial coding in which initial codes are linked and coded as a parent or final code. From the interviews and analysis, themes and sub-themes emerged as follows; Capability has as its sub themes human relation skills (emotional intelligence, self-management, time management, and synergy and conflict management), coaching, team work and learning). The sub-themes have already been discussed in the review of related literature as shown by the study references in Table 1.

Table 1. Theme and sub themes of the study

\begin{tabular}{|c|l|l|l|}
\hline S/No & Theme & Sub-theme & Study References in the Literature Review \\
\hline 1 & Capability & Learning & $\begin{array}{l}\text { Bontis et al. (2010), Edgar andAlan (2005), Egbu et al. (2005), Wang (2008), Shawn } \\
\text { et al. (2010). }\end{array}$ \\
\hline 2 & Capability & $\begin{array}{l}\text { Human Relation Skills (emotional } \\
\text { intelligence, self-management, } \\
\text { time management, synergy, } \\
\text { conflict management) }\end{array}$ & $\begin{array}{l}\text { Zaph (2002), Harrisson and Leitch (2005), Hitt et al. (2006), Baridam and Nwibere } \\
\text { (2008), Anugwom (2009), Ibok(2009), Ireland et al. (2009), Jaja (2009), Oparanma } \\
\text { (2010),Durst and Wilhem (2011), Avey et al. (2012) }\end{array}$ \\
\hline 3 & Capability & Team Work & Battilana and Casciaro(2012), Nelson (2006), Salami (2008), Barney(2005) \\
\hline 4 & Capability & Coaching & Hayton (2005), Hitt et al. (2006), Laohavichen et al, (2009), Kelloway et al., (2012) \\
\hline
\end{tabular}

\section{Findings}

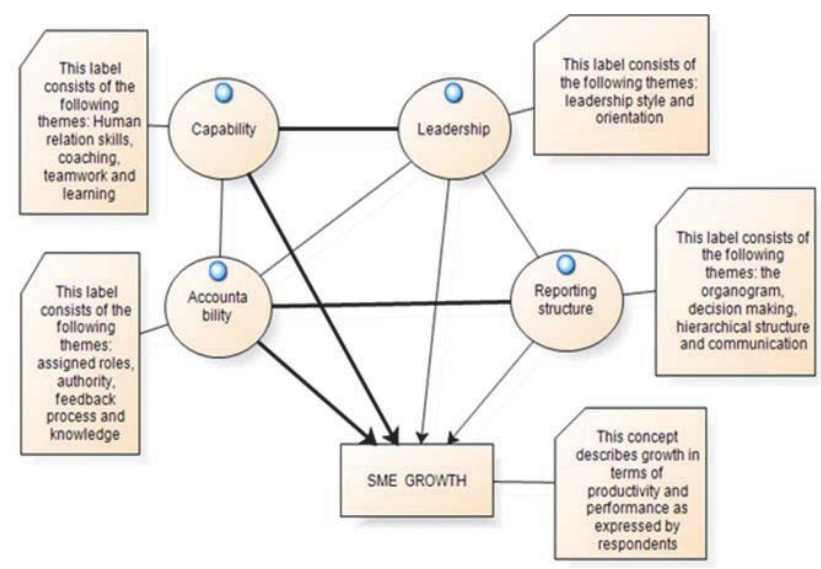

Figure 2. Nexus of findings between Organisational Health and growth of SMES 
The inter relationship between the dimensions of Organisational Health is depicted as a thin line without arrows. This means that there is no causal relationship. However the thick lines reveal a stronger relationship between the concerned dimensions. This is seen between capability and leadership on one hand and accountability and reporting structure on the other hand. The arrowed lines as determined by the Nvivo software analysis show influence from the predictor dimensions on SME growth. That is capability; leadership, accountability and reporting structure all have influence on growth of SMEs. However the thick arrowed lines as also determined by the Nvivo software analysis represent a stronger and more significant influence on SME Growth. From the findings of this study as shown in the model, capability and accountability have stronger influence on growth of SMEs compared to the influence of leadership and reporting structure. However capability has more influence compared to accountability.

\section{Discussion of Findings}

From the findings of this study as shown in the model in Figure 2, capability has a strong influence on growth of SMEs. The sub-themes under capability (skills and competencies) as found in this study include Human Relation Skills, coaching, team work and learning. These skills and competencies though important are lacking in the SMEs in Nigeria.

The HR skills include emotional intelligence, adaptability, flexibility, versatility and innovation all being coded as human relation skills (HRS). Human Relations (HR) skills and practices can be seen as important inputs in the social exchange process (Standford, 2011). As found in this study, educational and academic qualifications are necessary but human relations skills are expedient. This is as evidenced in the participants' responses.

'Educational, academic and technical skills are needed but human relational skills are paramount. Attitude, knowledge promotes and stabilizes the manager. Humans are with different dynamics and characters hence the manager must be competent in all ramifications ready to absorb faults and correct faults by teaching. Managers must be up to date in knowledge base, interact with subordinates, be abreast with current happenings and possess HR skills.'

'Our managers ought to have some level of Emotional intelligence to understand the different nature of employees working with them. Each employee has unique traits that need to be understood by our mangers to work well with us. By practicing human relation skills, there will be increase in performance and productivity. Besides the firm will be successful in accomplishment of set goals'

In the findings by Cummings and Worley (2001) and Zheng et al. (2010) it was discovered that organisational leadership has to skilfully apply managerial capabilities in order to bring about change that will positively influence Firm Growth; that is the survival and success of firms. This study found that employers on a daily basis interact with humans therefore pre requite skills needed in this daily interactions to achieve desired results and foster Firm Growth are crucial. Salami (2008) found that organisations consist of people who constantly interact. These interactions in organisations are the basis for the performance and ultimate growth of the organisation. It is in the interaction between employers and employees that managerial capabilities are exhibited.

Learning is earnestly desired as found in this study but impeded greatly due to the absence of training for employees and training of managers that do on the job coaching. In the review of related literature, Mark et al. (2009) provided evidence that the whole process of organisational learning engineered by prerequisite managerial capabilities produces better performance. The result was further advanced by Zheng et al. (2010) who discovered that dynamic managerial capability is essential to bring to bear organisational learning which positively affects performance for individuals and teams across organisational structures. Training is discovered to be lacking hence knowledge is never upgraded but obsolete therefore the coaching merely becomes recycling of obsolete knowledge which does not really help in a dynamic competitive system with the existence of globalisation. Jogulu (2010) found the importance of updated knowledge and stressed the need for managers in Nigerian SMEs to broaden their horizon in respect of knowledge acquisition and managerial capabilities to ensure sustainable Firm Growth. Learning, coaching and teamwork as sub themes that emerged in this study are crucial though lacking in most SMEs. This was found in this study and evidenced in the participants' responses.

'A fundamental challenge experienced is the absence of training. Employees are not normally sent for training. This affects performance negatively because the staff lacks up to date knowledge. It further adversely affects productivity and growth.'

'Constant training is needed but sometimes denied staff due to unavailability of funds.'

'On the other hand, the absence of training seems to be a hindrance to performance and growth. The world is dynamic and changing. To have competitive advantage, employees must continue to improve themselves on the job and not to 
rely on obsolete knowledge.'

'I encourage teamwork which enables share of ideas. I ensure that mentoring is practiced to build up staff capacity though some employees are difficult impacting knowledge on them.'

'1st Century management styles is no longer the command and obey structure but consistent teaching; not necessarily writing in form of query but persistently teaching and coaching except there is need to resort to writing for record purposes where there is no change. Knowledge dissemination is done to coach employees on the job.'

'Managers are regular and up to date on the job to disseminate knowledge to subordinates. Through the process of knowledge dissemination, managers coach employees on the job'

'As a manger, I replicate myself to the extent that when I am not around, the job continues. My absence does not stop the work flow in any way. I coach subordinates on the job, increase my knowledge on the job. I am flexible with employees. '

'Managers do on the job coaching. They coach staff which is limited to the extent of the job they know.'

'The knowledge of managers on the job is disseminated to subordinates through team work and coaching. The managers coach others on the job. The challenge here is that there is no training hence the knowledge of the managers is not upgraded and current. As a result it does not yield expected results on performance. This adversely affects productivity and growth.'

Some key words from the participants' responses are human relation skills, emotional intelligence, and team work, coaching, and training to boost learning, productivity and performance. These key words in the findings of this study have been discussed in the review of related literature. From the findings, learning though an important skill seems to be impeded due to lack of training. According to Bontis et al. (2010), learning is a valuable organisational skill to be desired hence provided evidence of a positive relationship between learning and performance. However Tan and Nasurdin (2011) contended that learning does not seem to be effective in Nigerian SMEs because most managers rely on obsolete knowledge. Bonny (2005) attributed the reliance on obsolete knowledge to insufficient funds for training to improve knowledge base. Giving credence to Tan and Nasurdin (2011) and the findings of this study, Okurame (2009) asserted that learning is a continuous process to improve organisational behaviours which include managerial skills, performance and foster growth but the reverse is the case in most Nigerian SMEs as they often rely on obsolete knowledge.

From the findings of this study, knowledge is disseminated to subordinates through coaching to foster firm growth. Teamwork is also encouraged to enhance dissemination of knowledge to ensure increase in performance and productivity. In line with this, Hayton (2005) asserted that managerial coaching can bring competitive advantages for organisations through employees' empowerment and motivation for performance, bringing more satisfaction and commitment thereby fostering growth. Nelson (2006) also asserted that teams enhance performance, increase responsiveness to customers hence gain competitive advantage and contribute to organisational effectiveness and health.

Sharif et al. (2010) contended that Emotional Intelligence (EI) is a human relation skill/ competence required by leaders in exhibiting managerial capabilities to foster Firm Growth. Whitener (2006) describes El as the ability to understand your own emotions and that of your followers. From the findings of this study, El is a human relation skill that managers are encouraged to possess to understand the nature of employees.

Summarily this study shows that managerial capability in form of skills and competencies are crucial to actualise the survival and success of SMEs. In consonance with this finding, Sharif et al. (2010) revealed that a complete revamping of Nigerian SMEs in the knowledge and implementation of managerial skills and competencies is expedient if SMEs must grow as expected and compete favourably with other SMEs in the global economy. Akintajo (2010) however argued that the challenge in Nigerian SMEs is not in the knowledge of managerial skills and competencies as revealed by Sharif et al. (2010) but is in the implementation of what is already known.

\section{Contribution}

The study finds that capability encompassing HR skills seems to be the ultimate foundation of Organisational Health. The study recommends that Entrepreneurs should put more emphasis on understanding industry conditions in order to choose the types of non-financing strategies that suit those conditions. Moreover, policy makers should understand the dimensions of Organisational Health especially managerial capability in order to provide adequate training which can further support SMEs' growth.

Having evaluated the perception of managerial capability as a dimension of Organisational Health in the Nigerian perspective, it is obvious that there exists a positive relationship between managerial capability as a soft factor dimension 
of Organisational Health and growth. Consistent with this, Quality management literature has shown that soft and hard factors inclusive of managerial capability are positively related to firm performance (Abdullah et al., 2009).

\section{References}

Abdullah, M., Jegag, U. \& Juan, J. (2009) The relationship of performance with soft factors and quality improvement. Total Quality Management 20 (7): 735- 748.

Ahiauzu (2011), African Industrial Man. Port Harcourt, Cimrat Publications

Ajala (2008) Changing Work Behaviour in the wake of Transformational Leadership, Strategic Management, 13 (2): 15-33.

Akinruwa, T.,Awolusi,O. \& Ibojo., Determinants of Small and Medium Enterprises (SMEs) Performance in Ekiti State, Nigeria: A Business Survey Approach. The European Journal of Humanities and Social Sciences 27(1):1396-1413

Akintayo (2010) Effects of Human Resource Systems on manufacturing performance and turnover, Academy of Management Journal; 37: $670-687$.

Almus, B. (2004) Socio-cultural Dimensions of Motivation and Management in Nigeria, African Journal of Public Administration and Management, 15 (1): 73-80.

Algoe, S. \& Fredrickson, B. (2011) Emotional Fitness and the Movement of Affective Science from laboratory to Field. American Psychologist, 66: 35- 42.

Amabile, T. (2009) Motivating creativity in organisations: On doing what you love and loving what you do. California Management Review, 40 (1): $372-400$.

Amir, B. (2012) The relationship between organisational structure and organisational justice. Asian Social Science, 8(4): 124-130.

Aniete, E. \& Akpan, S. (2012) Impediments to entrepreneurship development in the Niger Delta Region of Nigeria. Canadian social Science, 8(6):102-109

Anugwom (2009) What Employees Really Want: Data Matron, 41(5): 84.

Appelbaum,E., Thomas, B.,Peter, B.\& Arne,L. (2000) Manufacturing advantage-Why high performing work system pay off. Cornell University Press.

Argote, C \& Ingram, A. (2000) How Entrepreneurs Organise Firms under Conditions of Uncertainty. Journal of Management, 31(5) :776793.

Augustine, N. (2013) Reshaping an Industry: Lockheed Martin's survival story: Harvard Business Review, 75 (3) : 83 - 94.

Avey, J., Luthans F. \& Wernsing, S. (2012) Can Positive Employees Help Positive Organisational Change? Impact of Psychological Capital and Emotions on Relevant Attitudes and Behaviours. The Journal of Applied Behavioural Science, 44 (1):48-70.

Avolio et al. (2004) Transformational leadership and organisational commitment: Mediating role of psychological empowerment and moderating role of structural distance. Journal of Organizational Behaviour, 25: 951-968.

Balkundi, D.and Harrison, K. (2006) Sense making and emotions in organisations: Accounting for emotions in a rationalised context. Communication Studies, 57(2):215-238.

Baridam,D \& Nwibere,B.(2008) Understanding and Managing Organisational Behaviour Port Harcourt: Sherbrooke Associates.

Barney, J. (2005) Looking Inside for Competitive Advantage, Academy of Management Executive, 9: 49-61.

Baron \& Banaji (2006) Beyond social capital: The role of entrepreneurs' social Competence in their financial success. Journal of Business Venturing, 18(1): 41-60.

Barlett, K (2011) The Relationship between training and organisational commitment: AStudy in the Health Care Field, Human Resource Development Quarterly, 12(4):335-352.

Barney, J. (2005) Looking Inside for Competitive Advantage, Academy of Management Executive, 9: 49-61.

Bass, M. \& Rigio,E.(2006) Transformational leadership, The Psychologist-Manager Journal.10(2) :152-155.

Battilana, J. and Casciaro, T. (2012) Change agents, networks and Institutions: A contingency theory of Organisational Change. Academy of Management Journal, 55 (2): 381- 398.

Bonny,I. (2005) Improving strategic thinking: A Multilevel Approach. Leadership and Organisational Development Journal, 26(5): 336354.

Bontis, N., Sharabati,A. \& Jawad, S. (2010) Intellectual Capital and business performance in the pharmaceutical sector of Jordan. Management Decision 48(1): 105-131

Bowen,D \& Ostroff C. (2009) Understanding HRM and Firm Performance Leakages: The Role of the Strength of the HRM System. Academy of Management Review, 29 (2): 203-221.

Boxal,P. \& Purcell, J.(2008) Strategy and Human Resource Management. Management, Work and Organisations: Palgrave Macmillan

Cheng, Z., Lam, W., \& Zhong, J. (2010) Leader-Member Exchange and Member Performance: A new look at Individual-Level Negative Feedback-Seeking Behaviour andTeam-Level Empowerment Climate. Journal of Applied Psychology, 92(1): 202-212

Chew, J. and Chan C. (2008) HR practices, Organisational Commitment and Intention to Stay. International Journal Manpower, 29(6): 503-522.

Chio, L. (2006) Adjusting the Strategy of Financial Structure to propel Sustainable Economic Development, Macao. Monetary Authority of Macao.

Cummings A. \& Worley, C. (2001) HR practices, Organisational Commitment and Intention to Stay. International Journal Manpower, 29(6) : 503-522.

Davidson, D. (2009) Relationship between work team characteristics and effectiveness: A Replication and Extension. Personnel 
Psychology, 49: 429-52.

Durst, S. \& Wilhelm, S. (2011) Knowledge Management in practice: Insights into a Medium-Sized Enterprise's exposure to knowledge loss. Prometheus, 29 (1): 23-38.

Edgar, F. \& Alan, G. (2005). Human Resource Management Practice and Employee Attitude Different Measures- Different Results. Personal Review, 34 (5): 534-549.

Egbu, C., Hari, S. and Renukappa, S. (2005) Knowledge Management for sustainable Competitiveness in small and medium surveying practices. Structural Survey, 23(1), pp.7-21.

Eleni, P., Pere, S. and Xiaoni, L (2011) Entrepreneurship in the context of crisis: Identifying barriers and proposing strategies: International Atlantic Economic Society, 18: 111- 119.

Gastro, N. (2007). The Reality of Workplace Innovation and Competitiveness, Journal of Organisational Development, 41 (11): $162-174$.

Harrison, R. \& Leitch, C. (2005) Learning and organisation in the knowledge-based Information economy: Initial findings from a participatory action research case study. British Journal of Management, 11(2): 103-119.

Haslinda, A., Raduan, C. and Naresh, K. (2007a). Human Resource Development Practices in Malaysia: A case of manufacturing industries. European Journal of Social Sciences, 5(2): 37.

Haslinda, A., Raduan, C. and Naresh, K. (2007b). Human Resource Development Strategies: The Malaysian Scenario. Journal of Social Science, 3(4): 213-222.

Hayton, J. (2005) Promoting corporate entrepreneurship through human resource management practices: A review of empirical research". Human Resource Management Review, 15(1): 21-41.

Hemdi, M. \& Nasurdin, A. (2008) Investigating the influence of organisational justice on hotel employees' organisational citizenship behaviour intentions and turnover intentions. Journal of Human Resources in Hospitality and Tourism, Vol. 7(1): 1-23.

Heward, S., Hutchins, C., \& Kelleher, H. (2007) Organisational Change - Key to Capacity building and effective health promotion. Health Promotion International, 22 (2): $170-178$.

Hitt, M., Miller, C .and. Colella, A (2006) Organisational Behaviour: A strategic approach. John Wiley and Sons.

Ibok, N. (2009) Human Resources Practices and Organisational Citizenship Behaviour among sales employees, Ife Business Journal, $1(1): 78-91$.

Ireland, R., Covin, J. and Kuratko, D. (2009) Conceptualizing corporate entrepreneurship Strategy. Entrepreneurship: Theory \& Practice. 33 (1): 19-46.

Iveroth, E. (2010) A framework for the practice of leading global IT-enabled change California Management Review; 53(1):136-149.

Jaja, S. (2009) The Entrepreneurship Paradigm. Port Harcourt, Pearl Publisher.

Jaja S. \& Okwandu (2006) Effective Management of Human Resources for Business and Church Growth; International Multidisciplinary Journal Ethiopia, 9 (2), pp.189-196.

Jogulu, U. (2010) Culturally Linked Leadership Style. Leadership and Organisational Development Journal, 31(8): 705-719.

Jantunen, A., Puumalainen, K., Saarenketo, S. and Kylaheiko, K. (2005) Entrepreneurial orientation, dynamic capabilities and international performance. Journal of International Entrepreneurship, 3(3): 223-243.

Jusoh, M., Simun, M. and Chong, S. (2011). Expectation gaps, jobs satisfaction, and organisational commitment of fresh graduates: Roles of graduates, higher learning institutions and employers. Education/Training, 53 (6): 515-530.

Kavanagh, K. and Ashkanasy, J. (2006). The Influence of Proportional and Perceptional Conflict Composition on Team Performance. International Journal of Conflict Management, 11, pp. 56-73.

Khalili, A. (2012). Appraising the Impact of Gender Differences on Organisational Commitment: Empirical Evidence from a Private SME in Iran. International Journal of Business and Management, 7(5).

Kelloway, E., Heidi, W., Margaret, C. \& Hari, D. (2012) Positive Leadership and employee Well-being. Journal of Leadership and Organisational Studies: Canada. SAGE.

Ku, H., Mustapha, U. \& Gosh, S. (2010) Literature Review of past and present performance of Nigerian Manufacturing Sector. Journal of Engineering Manufacture, (22), 12: 1894- 1904.

Laohavichien, T. Fredendall, L. and Cantrell, R. (2009). The Effects of Transformational and Transactional Leadership on Quality Improvement, The Quality Management Journal, 16(2): 7-24.

Luthans, F. and Youssef, C (2007). Emerging Positive Organisation Behaviour. Journal of Management, 33: 321-349.

Mark, E., Marjorie, A. and Margaret, A. (2009) Dynamic Capabilities: Current Debates and Future Directions. British Journal of Management, 20 (1): 1- 8.

Mathew, (2009) Models of Change Management: A Reanalysis. Journal of Business Strategy, 6 (2): 7 - 17.

Miller, D., (2003) Configurations of strategy and structure towards a synthesis. Strategic Management Journal, 7(3): $233-250$.

Morrell, K., Loan-Clarke, J. \& Wilkinson, A. (2004) Organisational Change and employee turnover. Personnel Review, 33 (2):161-173.

Nelson, T. (2006) Strategic structure for organisational performance. International Journal of Management and Innovation, 2(2): 9-23.

Obisi, C. (2011) Employee Performance Appraisal and its Implication for Individual and Organisational Growth. Australian Journal of Business and Management Research, 1(9): $92-97$.

Ofeogbu, O. \& Akanbi, P. (2012) The influence of strategic agility on the perceived performance of manufacturing firms in Nigeria. International Business and Economics Research Journal, 11 (2):153 - 160.

Okurame,N.(2009) Coordination in Organisations: An Integrative Perspective. Academy of Management Annals, 3(1): 463-502.

Omachonu,F.\& Einspruch E. (2010) Process Management in the Public Sector. International Journal of Public Sector Management, 17(1): 81-107. 
Oparanma, A. (2010) The Organisational Culture and Corporate Performance in Nigeria. International Journal of African Studies, Issue 3: $34-40$

Pawa, B.\& Eastman, K. (2009). The nature and implications of contextual influences on transformational leadership: A Conceptual Examination. In Academy of Management Review22, pp.80-109.

Rahmati, V., Darouian, S. and Ahmadinia, H. (2012) A review on effect of culture Structure, technology and behaviour on organisations. Australian Journal of basic and applied sciences, 6(3): 128-135.

Rahman, S. (2004) Total Quality Management and Business Excellence. Strategic Management Journal, 15 (4): 15 - 37.

Robbins, S. and Judge, A. (2011).Organisational Behaviour (12th Ed.). Pearson Edition, Inc.

Salami, S. (2008) Demographic and psychological predicting organisational commitment among industrial workers. Anthropologist, 10(1): 31-38.

Sharif, M., Peou, C. \& Ali, J. (2010) Moderating effect of government policy on Entrepreneurship and growth performance of small medium enterprises in Cambodia. International Journal of Business and Management Science, 3 (1): $57-72$.

Shawn, M., Dennis, A., David, J. \& James, B. (2010) Transitional Identity as a facilitator of organisational identity change during a merger. Administrative Science Quarterly, 55: 397 - 438.

Shin, J. (2010) Impacts of performance-based accountability on institutional performance in the U.S. 60: 47-68.

Stanford, N. (2011) Organisational Health: An Integrated Approach to Building Optimum Performance. London, Kogan Page Limited.

Tan, C. \& Nasurdin, A. (2011). Human Resource Management Practices and Organisational Innovation: Assessing the Mediating Role of Knowledge Management Effectiveness. The Electronic Journal of Knowledge Management, 9 (2): 155-167.

Tanveer, N. (2010) Leadership Business Cafe.

Teece, D. (2009) Dynamic capabilities and strategic management. Oxford: Oxford University Press

Vesterinen, S., Suhonen, M., Isola, A. and Paasivaara, L. (2012) Nurse Managers' Leadership Styles in Finland. Hindawi Publishing Corporation, Nursing research and Practice, pp.1155-1164.

Wang, C. (2008) Entrepreneurial orientation, learning orientation, and firm performance. Entrepreneurship Theory and Practice, 32: 635656.

White, C., Vane, A., \& Stafford, G. (2010) Internal Communication, Information Satisfaction and sense of Community: the effect of personal influence. Journal of Public Relations Research, 22,(1): 65-84.

Whitener, E. (2006) Do high commitment Human Resource Practices affect Employee commitment? A Cross-Level Analysis Using Hierarchical Linear Modeling, Journal of Management, 27: 515-536.

Wood, S. (2005) The Four Pillars of HRM, Are They Connected? Human Resource Management Journal, 5(5): 221-233.

Yang, D. (2010). The Business Value of Emotions Management, Journal of Business Psychology 10 (7): 89-97.

Zheng, W., Yang, B., \& Mclean, G. (2010) Linking Organisational Culture, Structure Strategy and Organisational Effectiveness: Mediating Role of Knowledge Management. Journal of Business Research, 63: 763-771.

Zolo, M \& Winter, S. (2002) Deliberate learning and the evolution of dynamic capabilities. Organisation science 13(3):339-351. 